\section{BMJ Open \\ Respiratory \\ Research}

\title{
Lifestyle factors and experience of respiratory alarm symptoms in the general population
}

\author{
Lisa Maria Falk Sele, Kirubakaran Balasubramaniam, Sandra Elnegaard, \\ Jens Søndergaard, Dorte Ejg Jarbøl
}

To cite: Sele LMF,

Balasubramaniam K, Elnegaard S, et al. Lifestyle factors and experience of respiratory alarm symptoms in the general population. BMJ Open Resp Res 2015;2: e000101. doi:10.1136/ bmjresp-2015-000101

Received 8 July 2015 Revised 5 September 2015 Accepted 7 September 2015

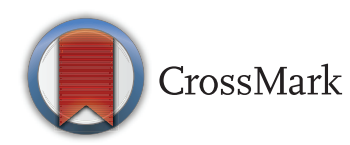

Department of Public Health, Research Unit of General Practice, University of Southern Denmark, Odense C, Denmark

Correspondence to Lisa Maria Falk Sele; Isele@health.sdu.dk

\section{ABSTRACT}

Background: The first step in the diagnosis of lung cancer is for individuals in the general population to recognise respiratory alarm symptoms (RAS).

Knowledge is sparse about RAS and factors associated with experiencing RAS in the general population. This study aimed to estimate the prevalence of RAS in the general population, and to analyse possible associations between lifestyle factors and experiencing RAS.

Methods: A web-based survey comprising 100000 individuals randomly selected from the Danish Civil Registration System. Items regarding experience of RAS (prolonged coughing, shortness of breath, coughing up blood and prolonged hoarseness) and self-reported lifestyle factors (smoking status, alcohol intake and body mass index) were included in the analysis.

Results: A total of 49706 individuals completed the questionnaire. 16 per cent reported at least one RAS. Prolonged coughing $(8.4 \%)$ and shortness of breath $(8 \%)$ were most prevalent, while coughing up blood was least prevalent $(0.1 \%)$. More men than women reported RAS $(p<0.001)$. Odds of reporting RAS increased with age $\left(P_{\text {trend }}<0.001\right)$. In men and women, former and current smoking was associated with reporting at least one RAS (former smoking: $\mathrm{OR}_{\text {men }}=1.42,95 \% \mathrm{Cl} 1.39$ to $1.56 ; \mathrm{R}_{\text {women }}=1.25,95 \%$ $\mathrm{Cl} 1.15$ to 1.36 ; current smoking: $\mathrm{OR}_{\text {men }}=2.58,95 \% \mathrm{Cl}$ 2.35 to $2.83 ; \mathrm{OR}_{\text {women }}=2.45,95 \% \mathrm{Cl} 2.25$ to 2.68 ). Individuals who were underweight or obese were significantly more likely to report at least one RAS. Odds of reporting at least one RAS increased with increasing alcohol intake for both genders $\left(P_{\text {trend }}<0.001\right)$.

Conclusions: RAS are common in the general population. Men experience more symptoms than women, and prevalence increases with age. Being a former or current smoker and being underweight or obese are positively associated with experiencing RAS. The likelihood of experiencing RAS increases with increasing alcohol intake. Future research should investigate healthcare seeking for RAS among individuals with different lifestyles.

\section{INTRODUCTION}

More than $90 \%$ of the population have experienced at least one symptom within the preceding week ${ }^{1}$ and $15 \%$ have experienced

\section{KEY MESSAGES}

Respiratory alarm symptoms and factors affecting the experience of these in the general population are important to understand and improve lung cancer diagnosis.

- Respiratory alarm symptoms are common in the general population, with $16 \%$ having experienced at least one respiratory alarm symptom within the preceding 4 weeks. Men report more respiratory alarm symptoms than women, and symptom reporting increases with age.

- Current smokers and underweight or obese individuals are more likely to report respiratory alarm symptoms. This might be useful in planning future population-based awareness campaigns.

an alarm symptom within the last year, ${ }^{2}$ substantiating the premise that symptoms are frequently experienced in the general population. ${ }^{1}$ Most symptoms are caused by benign conditions, while others are signs of serious disorders such as cancer. Recognition of symptoms is a vital part of lung cancer diagnosis, ${ }^{3}$ as most individuals with lung cancer present with symptoms at some point ${ }^{45}$ and because long patient intervals have been associated with poor survival rates among patients with lung cancer. ${ }^{6}$ Thus some countries have introduced cancer referral guidelines in order to improve the diagnostic interval, that is, to shorten the interval between the first symptom experience and diagnosis. ${ }^{7-9}$ The lung cancer guidelines define a number of respiratory alarm symptoms (RAS) that should raise suspicion about lung cancer when encountered in general practice. ${ }^{10}{ }^{11}$ However, the first step in the diagnosis of lung cancer is for individuals in the general population to recognise their symptoms. Current knowledge about RAS is mainly based on retrospective studies conducted among selected groups of patients already diagnosed with lung cancer, ${ }^{3}{ }^{12}$ or on 
presentation of RAS in general practice. ${ }^{13}$ Little is known about the prevalence of RAS in the general population.

Research has illustrated that symptom experiences are regarded as subjective interpretations of sensations and bodily changes, and that the interpretation process is affected by a complex mixture of multiple factors, including lifestyle factors, health perceptions and social network. ${ }^{14} 15$ Thus, the frequency of RAS may vary among subgroups in the general population. ${ }^{16}$ Smoking is a strong risk factor for developing lung cancer, ${ }^{17}$ and it is likely that smokers experience more RAS than nonsmokers. ${ }^{18}$ Other lifestyle factors such as alcohol intake and body mass index (BMI) can also affect the experience of RAS. Still, knowledge is sparse regarding RAS in the general population and how lifestyle factors influence the occurrence of RAS.

Awareness of lung cancer symptoms and risk factors is sparse. ${ }^{19}$ In order to improve awareness and healthcare seeking with cancer alarm symptoms in the general population, awareness campaigns have been launched. ${ }^{20} 21$ These awareness campaigns have focused on signs and symptoms of cancer, and have encouraged the general population to contact general practice when experiencing cancer alarm symptoms. The campaigns have had a wide focus on different symptoms and different cancer forms, which might have influenced the effect. ${ }^{22}{ }^{23}$ Therefore, more targeted campaigns have been suggested, emphasising the need for an enhanced understanding of the symptom experiences in different groups.

The objectives of this study were to obtain prevalence estimates of RAS in the general population and to analyse possible associations between lifestyle factors and RAS.

\section{METHODS}

\section{Study design and population}

This study was a nationwide cohort study of 100000 adults aged 20 years or older, randomly selected from the general population. The sample was drawn from the Danish Civil Registration System (CRS), in which all Danish citizens are registered with a unique personal identification number. The CRS contains information about every Danish resident's date of birth, gender, migration, etc. ${ }^{24}$ Each individual received a postal letter explaining the purpose of the study. A unique 12-digit login for a secure webpage was included in the letter, which provided access to a comprehensive web-based questionnaire. Participants without access to a computer, tablet or smartphone, were offered the opportunity to complete the survey as a telephone interview. A reminder letter was sent to the non-respondents 2 weeks after the invitational letter, and after an additional 2 weeks, the non-respondents were contacted by telephone and encouraged to participate. ${ }^{25}$

\section{The questionnaire}

A comprehensive questionnaire concerning the experience of 44 predefined specific and non-specific cancer alarm symptoms, as well as general and frequent symptoms, was developed. The questionnaire was based on standard rating scales, previously validated questionnaires and ad hoc items. The methodological framework for developing, pilot testing and field testing the questionnaire is described in detail elsewhere. ${ }^{25}$ Alarm symptoms for several different cancers (lung, gastrointestinal, urological and gynaecological) were selected based on a literature review that included national and international cancer referral guidelines. ${ }^{3} 51011$ In total, four RAS indicative of lung cancer form the basis of this paper: prolonged coughing, shortness of breath, coughing up blood and prolonged hoarseness. ${ }^{11}$

Respondents were asked whether they had experienced one or more RAS within the preceding 4 weeks. The wording of the question regarding symptoms was: 'Have you experienced any of the following bodily sensations, symptoms, or discomforts within the past 4 weeks?'. An item concerning when the symptom(s) occurred for the first time was also included. The response categories were: 'Less than 1 month ago', '13 months ago', '3-6 months ago' or 'more than 6 months ago'. Questions regarding current smoking status, average alcohol intake, weight and height were also asked.

\section{Statistical analyses}

In the cancer referral guidelines, coughing and hoarseness are defined as RAS when they are prolonged, that is, last for more than 4-6 and 3-4 weeks, respectively. ${ }^{9}$ To approach concordance with these definitions, only respondents who had experienced the symptom for the first time more than 1 month ago were considered to have experienced prolonged coughing and prolonged hoarseness.

Covariates considered in the statistical analyses were gender, age, smoking status, alcohol intake and BMI. The respondents were divided into the following age groups: $20-39,40-59,60-79$ and $\geq 80$ years. Smoking status was categorised as current, former and never smoker. Alcohol intake was categorised in units per week: $0,1-7,8-21$ and $\geq 22$ units/week. BMI was calculated from height and weight, and categorised according to WHO guidelines as follows: underweight (BMI $<18.5$ ), normal weight (BMI 18.5-24.9), overweight (BMI 25-29.9) and obese (BMI $\geq 30) .{ }^{20}$

Prevalence estimates were calculated for reporting at least one RAS and for each individual RAS. One symptom was defined as having experienced at least one, but possibly more than one, of the four RAS. CIs for all prevalence estimates were calculated using the binomial distribution. Differences between reporting of RAS were tested for each covariate using either the $\chi^{2}$ test or Fisher's exact test, as appropriate.

Logistic regression models were used to test for interaction between gender and each covariate with regard to at least one symptom, prolonged coughing, shortness of breath or prolonged hoarseness, respectively. The tests 
were made with Bonferroni adjustment to account for multiple testing. A test for interaction was not made for coughing up blood, because of the small number of respondents that reported this symptom.

To evaluate collinearity between lifestyle factors, correlation coefficients were calculated with Spearman's rank correlation. Multivariate logistic regression models were used to analyse the association between each covariate and reporting of at least one RAS, and each individual RAS. Owing to interactions, the analyses were stratified with respect to gender. Adjustments were made for possible confounders: age, smoking status, alcohol intake and BMI.

Linear trends in the reporting of RAS were tested with logistic regression models for age and alcohol intake. For alcohol intake, the test for trend only included respondents who drank more than 0 units/week.

All statistical tests were subjected to a significance threshold of 0.05 . Data analyses were conducted using Stata IC 13 software.

\section{RESULTS}

Of the 100000 randomly selected individuals, 4747 $(4.7 \%)$ were not eligible because they had died, could not be reached due to unknown address, were suffering from severe illnesses (including dementia), had language problems, or had moved abroad. Of the 95253 (95.3\%) eligible individuals, 49706 completed the questionnaire, yielding an overall response rate of $52.2 \%$ (figure 1). Some $53.2 \%$ of respondents were women, compared to $48.6 \%$ of non-respondents. The median age of respondents was 52 years (IQR 40-64). In comparison, median age of non-respondents was 50 years (IQR 36-66).
Table 1 lists the prevalence estimates for reporting at least one RAS and each individual RAS during the preceding 4 weeks. A total of $7870(16 \%)$ respondents reported at least one RAS. Prolonged coughing (8.5\%) and shortness of breath $(8 \%)$ were most common, prolonged hoarseness $(3.4 \%)$ was less common and coughing up blood $(0.1 \%)$ was rare.

In general, more men than women reported RAS $(p<0.05)$. However, the difference between genders was not significant for prolonged hoarseness. The prevalence estimates for symptom experiences differed significantly with respect to age group $(p<0.001)$, smoking status $(p<0.001)$, alcohol intake $(p<0.001)$ and BMI $(p<0.001)$, although not significantly for coughing up blood (table 1).

Tables 2 and 3 depict the ORs of associations between age, smoking status, alcohol intake, BMI, and reporting of RAS for men and women, respectively. Since low correlations were observed between lifestyle factors, they were all included in the same multivariate logistic regression models.

\section{Age}

Odds of reporting at least one RAS, prolonged coughing, shortness of breath or prolonged hoarseness increased with increasing age $\left(\mathrm{P}_{\text {trend }}<0.001\right)$ among men (table 2) and among women (table 3 ).

\section{Smoking status}

Regarding both genders, odds of reporting at least one RAS were significantly higher for former smokers $\left(\mathrm{OR}_{\mathrm{men}}=1.42,95 \%\right.$ CI 1.30 to 1.56 ; $\mathrm{OR}_{\text {women }}=1.25,95 \%$ CI 1.15 to 1.36$)$ and current smokers $\left(\mathrm{OR}_{\mathrm{men}}=2.58,95 \%\right.$ CI 2.35 to 2.83 ; $\mathrm{OR}_{\text {women }}=2.45,95 \%$ CI 2.25 to 2.68 )
Figure 1 Study cohort.

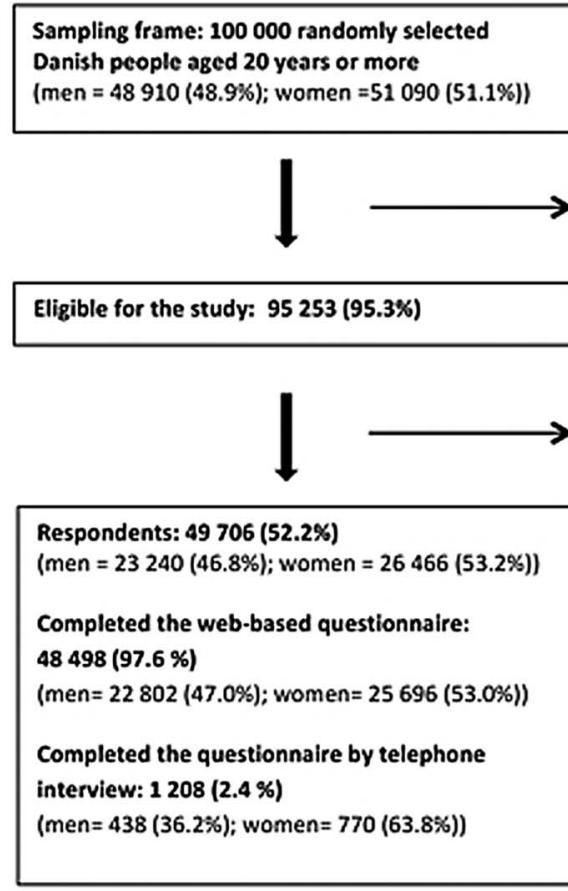

Excluded: 4747 (4.7\%)

Dead: 315

Addresses unknown: 961

Suffering from severe illness (including dementia): 1972 Language problems: 885

Moved abroad: 614

Non-respondents: 45547 (47.8\%)

(men $=23407(51.4 \%)$, women $=22,140(48.6 \%)$

Not wishing to participate (indicated by telephone/email or postal contact): $\mathbf{2 5} 690$

Indicated 'other reasons' for non-participation: $\mathbf{3 1 8}$

Questionnaire not completed (no achieved contact in the reminder procedure): 19539 


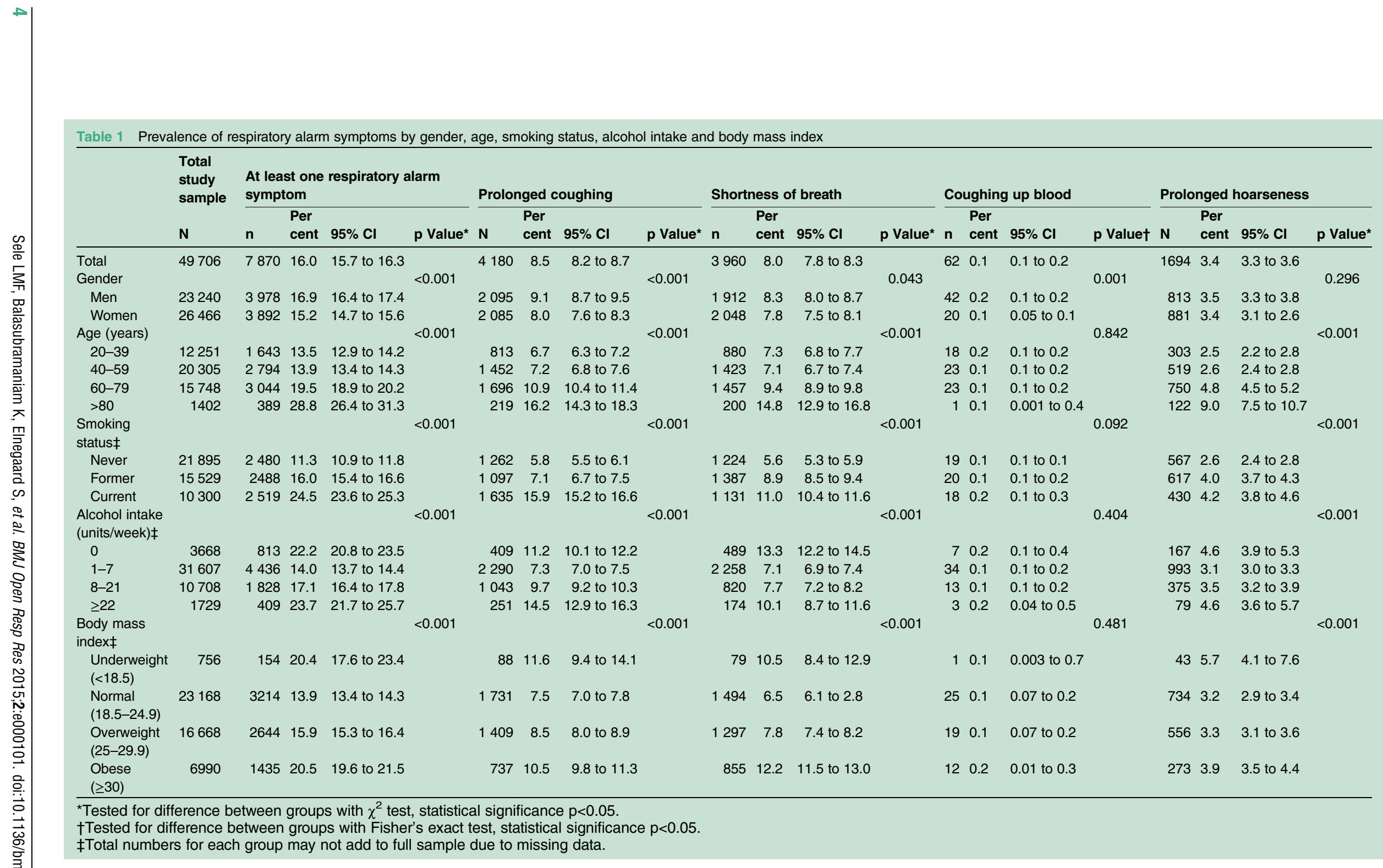

'746।лरdos

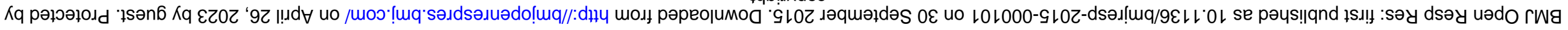


Table 2 Associations between lifestyle factors and experience of respiratory alarm symptoms for men

\begin{tabular}{|c|c|c|c|c|c|c|c|c|c|c|c|c|c|c|c|c|c|c|c|c|}
\hline & \multicolumn{4}{|c|}{$\begin{array}{l}\text { At least one respiratory alarm } \\
\text { symptom }\end{array}$} & \multicolumn{4}{|c|}{ Prolonged coughing } & \multicolumn{4}{|c|}{ Shortness of breath } & \multicolumn{4}{|c|}{ Coughing up blood } & \multicolumn{4}{|c|}{ Prolonged hoarseness } \\
\hline & OR & $\begin{array}{l}\text { Adjusted } \\
\text { OR }^{\star}\end{array}$ & $95 \% \mathrm{Cl}$ & $P_{\text {trend }} t$ & OR & $\begin{array}{l}\text { Adjusted } \\
\mathrm{OR}^{\star}\end{array}$ & $95 \% \mathrm{Cl}$ & $P_{\text {trend }} t$ & OR & $\begin{array}{l}\text { Adjusted } \\
\text { OR }^{\star}\end{array}$ & $95 \% \mathrm{Cl}$ & $P_{\text {trend }} t$ & OR & $\begin{array}{l}\text { Adjusted } \\
\text { OR }^{\star}\end{array}$ & $95 \% \mathrm{Cl}$ & $P_{\text {trend }} t$ & OR & $\begin{array}{l}\text { Adjusted } \\
\text { OR }^{\star}\end{array}$ & $95 \% \mathrm{Cl}$ & $P_{\text {trend }} t$ \\
\hline Age (years) & & & & $<0.001$ & & & & $<0.001$ & & & & $<0.001$ & & & & 0.222 & & & & $<0.001$ \\
\hline $20-39$ & 1 & 1 & & & 1 & 1 & & & 1 & 1 & & & 1 & 1 & & & 1 & 1 & & \\
\hline $40-59$ & 1.03 & 0.97 & 0.88 to 1.08 & & 0.97 & 0.97 & 0.85 to 1.11 & & 1.07 & 0.95 & 0.83 to 1.09 & & 0.64 & 0.44 & 0.19 to 0.99 & & 1.00 & 0.98 & 0.78 to 1.23 & \\
\hline $60-79$ & 1.54 & 1.40 & 1.27 to 1.55 & & 1.46 & 1.49 & 1.30 to 1.70 & & 1.37 & 1.13 & 0.99 to 1.30 & & 0.60 & 0.56 & 0.25 to 1.28 & & 2.16 & 1.97 & 1.59 to 2.44 & \\
\hline$>80$ & 2.33 & 2.32 & 1.89 to 2.84 & & 2.47 & 3.02 & 2.36 to 3.85 & & 2.04 & 2.21 & 1.95 to 2.51 & & 0.59 & 0.64 & 0.08 to 5.06 & & 3.64 & 3.36 & 2.38 to 4.73 & \\
\hline \multicolumn{21}{|l|}{ Smoking status } \\
\hline Never & 1 & 1 & & & 1 & 1 & & & 1 & 1 & & & 1 & 1 & & & 1 & 1 & & \\
\hline Former & 1.68 & 1.42 & 1.30 to 1.56 & & 1.36 & 1.11 & 0.98 to 1.26 & & 1.91 & 1.71 & 1.51 to 1.94 & & 1.21 & 1.35 & 0.58 to 3.13 & & 2.01 & 1.62 & 1.36 to 1.94 & \\
\hline Current & 2.70 & 2.58 & 2.35 to 2.83 & & 3.28 & 3.09 & 2.75 to 3.47 & & 2.25 & 2.13 & 1.85 to 2.45 & & 2.12 & 2.19 & 1.00 to 4.78 & & 1.65 & 1.54 & 1.27 to 1.88 & \\
\hline $\begin{array}{l}\text { Alcohol intake } \\
\text { (units/week) }\end{array}$ & & & & $<0.001 \ddagger$ & & & & $<0.001 \ddagger$ & & & & $0.269 \ddagger$ & & & & $0.955 \ddagger$ & & & & 0.823 \\
\hline 0 & 1 & 1 & & & 1 & 1 & & & 1 & 1 & & & 1 & 1 & & & 1 & 1 & & \\
\hline $1-7$ & 0.49 & 0.58 & 0.50 to 0.67 & & 0.54 & 0.65 & 0.54 to 0.79 & & 0.45 & 0.53 & 0.44 to 0.64 & & 0.55 & 0.70 & 0.21 to 2.35 & & 0.62 & 0.66 & 0.50 to 0.87 & \\
\hline $8-21$ & 0.61 & 0.62 & 0.54 to 0.73 & & 0.69 & 0.75 & 0.62 to 0.91 & & 0.51 & 0.52 & 0.43 to 0.63 & & 0.56 & 0.62 & 0.17 to 2.26 & & 0.64 & 0.59 & 0.44 to 0.80 & \\
\hline$\geq 22$ & 0.88 & 0.79 & 0.66 to 0.96 & & 1.05 & 0.98 & 0.78 to 1.24 & & 0.68 & 0.62 & 0.49 to 0.79 & & 0.78 & 0.82 & 0.16 to 4.08 & & 0.83 & 0.72 & 0.50 to 1.04 & \\
\hline \multicolumn{21}{|l|}{$\begin{array}{l}\text { Body mass } \\
\text { index }\end{array}$} \\
\hline $\begin{array}{l}\text { Underweight } \\
(<18.5)\end{array}$ & 2.27 & 2.01 & 1.31 to 3.07 & & 2.37 & 2.01 & 1.22 to 3.32 & & 1.52 & 1.30 & 0.69 to 2.46 & & - & - & - & & 2.95 & 2.80 & 1.47 to 5.33 & \\
\hline $\begin{array}{l}\text { Normal } \\
(18.5-24.9)\end{array}$ & 1 & 1 & & & 1 & 1 & & & 1 & 1 & & & 1 & 1 & & & 1 & 1 & & \\
\hline $\begin{array}{l}\text { Overweight } \\
\text { (25-29.9) }\end{array}$ & 1.11 & 1.11 & 1.03 to 1.21 & & 1.01 & 1.05 & 0.94 to 1.16 & & 1.26 & 1.25 & 1.11 to 1.40 & & 0.91 & 1.01 & 0.48 to 2.11 & & 0.98 & 0.91 & 0.77 to 1.07 & \\
\hline Obese $(\geq 30)$ & 1.57 & 1.60 & 1.44 to 1.77 & & 1.29 & 1.38 & 1.21 to 1.59 & & 2.16 & 2.13 & 1.86 to 2.43 & & 1.67 & 1.88 & 0.81 to 4.36 & & 1.13 & 1.04 & 0.84 to 1.29 & \\
\hline
\end{tabular}

Bold indicates statistical significance at $5 \%$ level.

*Adjusted for: age, smoking status, alcohol intake and body mass index.

†Statistically significant $P_{\text {test }}$ for trend $<0.05$.

fOnly tested for those who drink more than 0 units/week. 


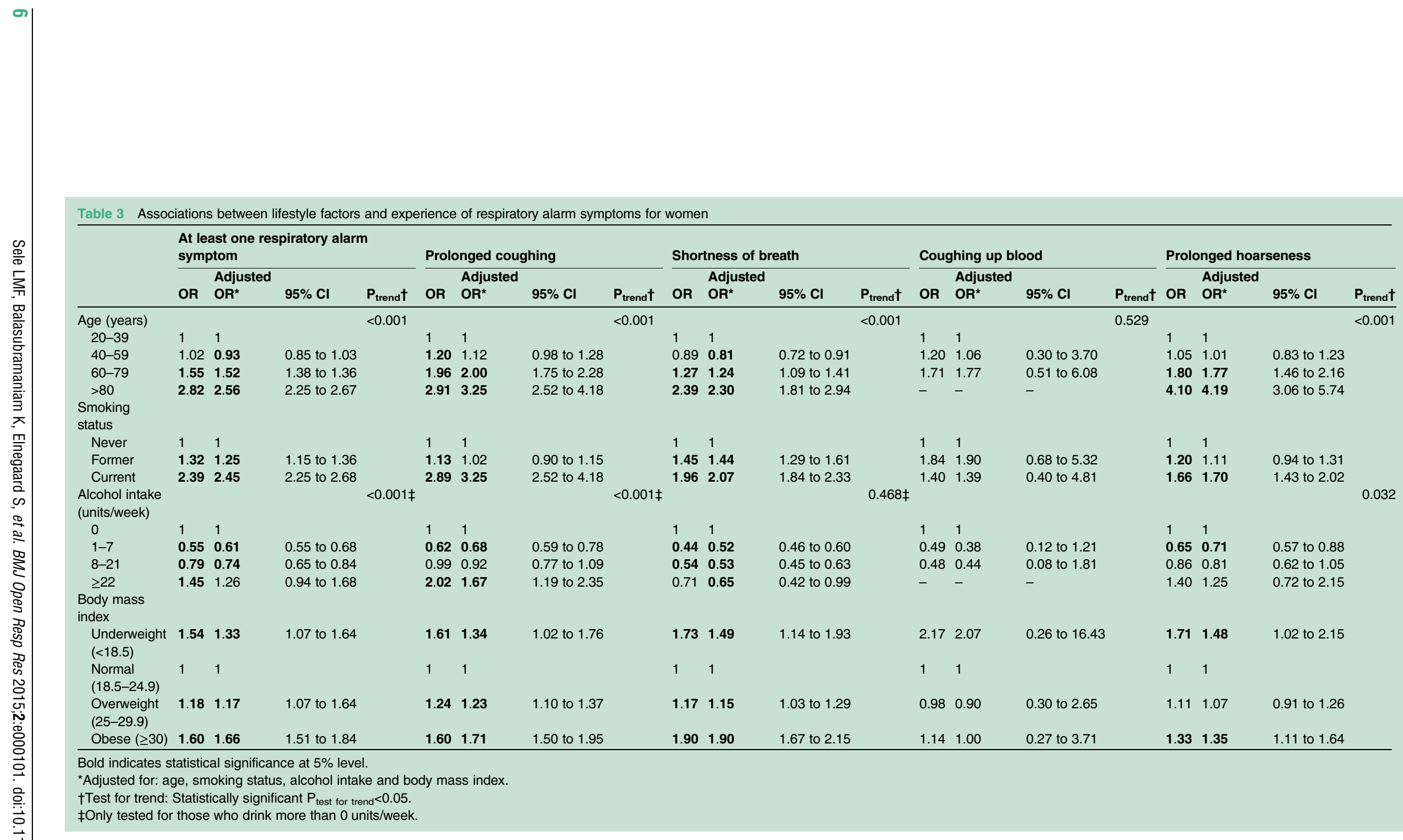

'746!ıरdos

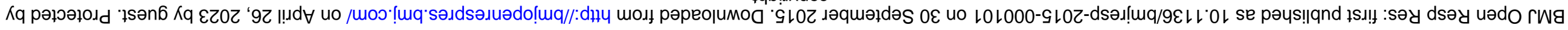


than for never smokers. Current smoking was significantly associated with reporting prolonged coughing, shortness of breath and prolonged hoarseness for both genders (tables 2 and 3), and, among men, with coughing up blood (table 2).

\section{Alcohol intake}

Overall, individuals reporting an alcohol intake of 1-7 or 8-21 units/week had significantly lower odds of reporting RAS than those who reported drinking 0 units/week. Among both men and women who reported alcohol intake $>0$ units/week, we observed a trend of increased reporting of at least one RAS with increasing alcohol intake $\left(\mathrm{P}_{\text {trend }}<0.001\right)$. This was also the case for reporting prolonged coughing in both men and women $\left(\mathrm{P}_{\text {trend }}<0.001\right)$, and, among women, for prolonged hoarseness $\left(\mathrm{P}_{\text {trend }}=0.032\right.$; tables 2 and 3$)$.

\section{Body mass index}

In men and women, odds of reporting at least one RAS were significantly higher for individuals who were underweight $\left(\mathrm{OR}_{\mathrm{men}}=2.01, \quad 95 \% \quad \mathrm{CI} \quad 1.31\right.$ to 3.07 ; $\mathrm{OR}_{\text {women }}=1.33,95 \%$ CI 1.07 to 1.64 ) or obese $\left(\mathrm{OR}_{\mathrm{men}}=1.60,95 \%\right.$ CI 1.44 to $1.77 ; \mathrm{OR}_{\mathrm{women}}=1.66,95 \%$ CI 1.51 to 1.84) compared to individuals at normal weight (tables 2 and 3). Being underweight or obese was also significantly associated with reporting prolonged coughing among both men and women, and, among women, for shortness of breath and prolonged hoarseness (tables 2 and 3 ).

\section{DISCUSSION}

\section{Summary and main findings}

This study shows that RAS are common in the general population. Sixteen per cent of respondents reported at least one symptom. The most prevalent symptoms were prolonged coughing $(8.5 \%)$ and shortness of breath $(8 \%)$, while prolonged hoarseness $(3.4 \%)$ and coughing up blood $(0.1 \%)$ were least frequent. Men more frequently reported RAS, and odds of reporting RAS increased with age for both men and women. Lifestyle factors were significantly associated with experiencing RAS. Former and current smokers were more likely to report RAS than never smokers. Being underweight or obese was positively associated with reporting RAS. Among individuals who reported alcohol intake, odds of reporting RAS increased with increasing alcohol intake; however, individuals reporting an alcohol intake were less likely to report RAS than individuals with no alcohol intake.

\section{Strength and limitations}

A major strength of this study is the large study sample of 100000 randomly selected Danish individuals. The response rate $(52.2 \%)$ is similar to or exceeds that of previous population-based studies. ${ }^{18}{ }^{26}$ Although more of the respondents were women and the respondents were slightly older than the non-respondents, the respondents were fairly representative of the general adult Danish population. However, we were unable to eliminate the possibility that the respondents could differ from the non-respondents regarding other parameters, which might include a risk of overestimating or underestimating the prevalence.

Willingness to respond to the questionnaire might depend on the presence of symptoms. ${ }^{27} 28$ If individuals with many RAS were more willing to answer, the prevalence estimates might have been overestimated. However, individuals with many RAS might not have the surplus of energy to respond to a comprehensive questionnaire, which would counterbalance the aforementioned.

The fact that the questionnaire was web-based could have prevented some individuals, for example, the elderly, from participating in the survey. ${ }^{29}$ We sought to minimise this possibility by offering individuals without a computer, smartphone, or tablet, the opportunity to conduct the survey as a telephone interview. Nevertheless, a lower response rate was still found in the oldest age group, which might indicate that the telephone interview did not completely compensate for the possible selection. The lower response rate might result in bias, because older respondents might be in better health than older non-respondents. Thus, the prevalence of RAS among the oldest age group might be even higher than estimated in the present study.

Information about symptom experiences was selfreported, and respondents were asked to recall symptom experiences within the 4 weeks preceding completion of the questionnaire. The time of recall was chosen because it seems reasonable to assume that individuals can recall symptom experiences fairly accurately within that timespan. ${ }^{30}{ }^{31}$ However, recall bias cannot be eliminated. Some respondents may misplace older symptoms in the specific time period, providing an overestimation of prevalence. ${ }^{32}$ However, others may recall fewer symptoms due to, for example, memory decay, providing an underestimation of the prevalence. ${ }^{33}$

Reporting of lifestyle factors might be biased due to a general tendency to underreport smoking status, alcohol intake and weight, and a tendency to over-report height. $^{34-36}$ However, web-based questionnaires have been suggested to enhance the perception of privacy among respondents, increasing the reliability of answers regarding sensitive issues, such as lifestyle factors. ${ }^{37} 38$ Although avoidance of misclassification might not be possible, the questionnaire was comprehensive and considered a broad range of different symptom experiences and topics. This makes it unlikely that, for example, the experience of RAS addressed initially in the questionnaire has affected answers regarding lifestyle factors addressed later in the questionnaire. A possible misclassification would, therefore, be nondifferentiated. $^{39}$

The analyses were adjusted for age and each lifestyle factor. ${ }^{17}{ }^{40}{ }^{41}$ Comorbidity was considered a potential 
confounder, but was not included in the model because we found that it was more likely to be a mediator of the association between lifestyle factors and experience of RAS.

\section{Discussion of results and comparison with the existing literature}

Few studies have estimated the prevalence of respiratory symptoms in the general population. ${ }^{2} 182642$ McAteer et $a l^{18}$ found the prevalence of coughing to be $17.8 \%$, compared with $8.5 \%$ in the present study, while Svendsen $e t a l^{2}$ observed a prevalence of coughing of $6.5 \%$. One explanation for these differences might be the different time interval for reporting symptom experiences. McAteer et $a l^{18}$ did not restrict the duration of coughing, while the present study only included coughing that lasted longer than 4 weeks, and Svendsen et $a l^{2}$ included individuals who experienced coughing for more than 6 weeks. Prevalence estimates for shortness of breath and coughing up blood in the McAteer study were comparable to those in the present study. ${ }^{18}$ Petrie et $a l^{42}$ and Whitaker $e t a l^{26}$ observed higher prevalence of symptom experiences. Petrie $e t a l^{42}$ published a prevalence of coughing of $28.3 \%$ and a prevalence of shortness of breath of $13.2 \%$; however, they collected data during flu and cold season. Whitaker et $a l^{26}$ reported a prevalence of persistent coughing of $20.3 \%$, but used a broader definition of persistent coughing than the present study, and also included symptom experiences within the last 3 months.

In contrast to the findings of the present study, McAteer $e t a l^{18}$ observed no gender difference in the prevalence estimates of coughing and shortness of breath. Furthermore, older age groups reported significantly lower odds of coughing and shortness of breath, ${ }^{18}$ while the present study demonstrated higher odds of reporting RAS in the oldest age groups. The age span differed between McAteer et $a l^{18}{ }^{18}$ who only included individuals aged 60 years or younger, and the present study, which included all individuals aged 20 years or older. However, this difference does not explain the different findings in the two studies.

The present study shows that RAS are common. RAS are defined as warning signs of lung cancer, but may be signs of more benign conditions, as well. Distinguishing between benign conditions and serious diseases such as cancer is difficult, and poses a challenge for physicians as well as the general population. Experiencing and interpreting symptoms is a complex process that involves several parameters. ${ }^{14}$ Qualitative studies have mentioned that individuals in the general population often consider age, former experienced symptoms and lifestyle factors in their interpretation of symptoms. ${ }^{16} 43$

In the present study, current and former smokers were more likely to report RAS than never smokers. The results were expected, considering that smoking is a risk factor for several respiratory diseases, thus likely leading to symptoms. ${ }^{17} 41$ Studies have shown that current smokers have a tendency to normalise their symptoms. ${ }^{44} 45$ If that is the case, then the odds of current smokers experiencing RAS might be underestimated in the present study.

Individuals drinking 1-7 and 8-21 units/week were less likely to report RAS than individuals who never drink alcohol. One possible explanation for this is that the never drinkers represent a group characterised by morbidity resulting in many symptoms and inability to drink alcohol. Another, possibly more plausible explanation, is that the never drinkers may represent a group that has made a deliberate choice of healthy living, ${ }^{46}$ and are thus more aware of symptom experiences and report more symptoms when asked during completion of a questionnaire. This theory is not supported in the current literature, but could be investigated in future research.

Underweight and obese individuals were more likely to report RAS than individuals with normal weight. One possible explanation, at least for shortness of breath, is that underweight and obese individuals experience more of a strain on their bodies than individuals at normal weight. Underweight or obese individuals might also be more aware of their bodies, resulting in remembering and reporting more symptom experiences when asked during completion of a questionnaire. These hypotheses have not been tested in previous studies, but could be addressed in future studies.

\section{Conclusion and implications}

This population-based study showed that $16 \%$ of the general population experienced at least one RAS within the preceding 4 weeks and that lifestyle factors influenced the experience of RAS.

The first step in the diagnosis of lung cancer is for individuals with RAS to recognise their symptoms. Knowledge about the prevalence of RAS in the general population and in subgroups with different lifestyles might be useful in the understanding of the diagnostic pathway of lung cancer, and may help policymakers to develop targeted campaigns. Although many people experience RAS, few are diagnosed with lung cancer. Nevertheless, it is necessary to seek healthcare in order for lung cancer to be diagnosed. Smoking, older age and being underweight or obese are positively associated with experiencing RAS. Whether these factors also influence healthcare-seeking when RAS are experienced is unknown. Future research should investigate healthcareseeking behaviour among subgroups with different lifestyles.

Acknowledgements This survey was conducted in collaboration between the University of Southern Denmark and Aarhus University. The project is part of the research portfolio at the Research Centre for Cancer Diagnosis in Primary Care (CaP). Dorte Ejg Jarbøl, Sanne Rasmussen, Kirubakaran

Balasubramaniam, Sandra Elnegaard, Rikke Pilsgaard Svendsen, Anette Fischer Pedersen, Rikke Sand Andersen and Peter Vedsted developed the 
questionnaire used in the study. The authors would like to thank Lise Keller Stark and San Francisco Edit for proofreading the manuscript and Pia Vedsted Larsen for statistical guidance. We thank the Novo Nordisk Foundation, the Danish Cancer Society, the Danish Council of Independent Research and the PLU Foundation, for financial support.

Contributors LMFS was mainly responsible for preparing the manuscript. KB, SE and DEJ participated in the design of the study and development of the questionnaire, and were responsible for the logistics concerning the survey and the drafting of the manuscript. JS participated in the design of the study, development of the questionnaire and drafting of the manuscript. All the authors read and approved the final manuscript.

Funding Novo Nordisk; Kræftens Bekæmpelse; Sundhed og Sygdom, Det Frie Forskningsråd.

\section{Competing interests None declared.}

Ethics approval The Regional Scientific Ethics Committee for Southern Denmark evaluated the project and concluded that the project was not notifiable and could be implemented according to Danish legislation. The study participants were clearly informed that there would be no clinical follow-up and that they should contact their own GP in case of concern or worry. The project has been approved by the Danish Data Protection Agency (journal number 2011-41-6651).

Provenance and peer review Not commissioned; externally peer reviewed.

Data sharing statements No additional data are available.

Open Access This is an Open Access article distributed in accordance with the Creative Commons Attribution Non Commercial (CC BY-NC 4.0) license, which permits others to distribute, remix, adapt, build upon this work noncommercially, and license their derivative works on different terms, provided the original work is properly cited and the use is non-commercial. See: http:// creativecommons.org/licenses/by-nc/4.0/

\section{REFERENCES}

1. Kjeldsberg M, Tschudi-Madsen H, Dalen I, et al. Symptom reporting in a general population in Norway: results from the Ullensaker study. Scand J Prim Health Care 2013;31:36-42.

2. Svendsen RP, Stovring H, Hansen BL, et al. Prevalence of cancer alarm symptoms: a population-based cross-sectional study. Scand J Prim Health Care 2010;28:132-7.

3. Hamilton W, Peters TJ, Round A, et al. What are the clinical features of lung cancer before the diagnosis is made? A population based case-control study. Thorax 2005;60:1059-65.

4. Shim J, Brindle L, Simon M, et al. A systematic review of symptomatic diagnosis of lung cancer. Fam Pract 2014;31:137-48.

5. Beckles MA, Spiro SG, Colice GL, et al. Initial evaluation of the patient with lung cancer: symptoms, signs, laboratory tests, and paraneoplastic syndromes. Chest 2003;123:97S-104S.

6. Torring ML, Frydenberg M, Hansen RP, et al. Evidence of increasing mortality with longer diagnostic intervals for five common cancers: a cohort study in primary care. Eur J Cancer 2013;49:2187-98.

7. Weller D, Vedsted P, Rubin G, et al. The Aarhus statement: improving design and reporting of studies on early cancer diagnosis. Br J Cancer 2012;106:1262-7.

8. NICE. Referal Guidelines for suspected cancer 2005. http://www. nice.org.uk/guidance/cg27/ (accessed: 15 Jan 2015).

9. Sundhedsstyrelsen (Danish Health and Medicine Authority). National Cancer Plan II 2005. https://sundhedsstyrelsen.dk/da/sundhed/ folkesygdomme/kraeft/nationale-planer/kraeftplan-ii (accessed: 12 Mar 2015).

10. NICE. Lung cancer: The diagnosis and treatment of lung cancer 2011. http://www.nice.org.uk/guidance/cg121 (accessed: 4 Dec 2014).

11. Sundhedsstyrelsen (Danish Health and Medicine Authority). Indgange til Lungekræftpakken 2012. http://sundhedsstyrelsen.dk/ da/sundhed/folkesygdomme/kraeft/pakkeforloeb/indgange (accessed: 12 Mar 2015).

12. Corner J, Hopkinson J, Fitzsimmons $D$, et al. Is late diagnosis of lung cancer inevitable? Interview study of patients' recollections of symptoms before diagnosis. Thorax 2005;60:314-19.

13. Brindle L, Pope C, Corner J, et al. Eliciting symptoms interpreted as normal by patients with early-stage lung cancer: could GP elicitation of normalised symptoms reduce delay in diagnosis? Cross-sectional interview study. BMJ Open 2012;2:pii: e001977.

14. Rosendal M, Jarbol DE, Pedersen AF, et al. Multiple perspectives on symptom interpretation in primary care research. BMC Fam Pract 2013;14:167.

15. Andersen RS, Paarup B, Vedsted P, et al. 'Containment' as an analytical framework for understanding patient delay: a qualitative study of cancer patients' symptom interpretation processes. Soc $\mathrm{Sci}$ Med 2010;71:378-85.

16. Birt L, Hall N, Emery J, et al. Responding to symptoms suggestive of lung cancer: a qualitative interview study. BMJ Open Respir Res 2014;1:e000067.

17. Dela Cruz CS, Tanoue LT, Matthay RA. Lung cancer: epidemiology, etiology, and prevention. Clin Chest Med 2011;32:605-44.

18. McAteer A, Elliott AM, Hannaford PC. Ascertaining the size of the symptom iceberg in a UK-wide community-based survey. $\mathrm{Br} J$ Gen Pract 2011;61:e1-11.

19. Simon AE, Juszczyk D, Smyth N, et al. Knowledge of lung cancer symptoms and risk factors in the U.K.: development of a measure and results from a population-based survey. Thorax 2012;67: 426-32.

20. Richards MA. The National Awareness and Early Diagnosis Initiative in England: assembling the evidence. Br J Cancer 2009;101(Suppl 2):S1-4.

21. Cancer Research UK. Be Clear on Cancer-Lung Cancer Campain 2014. http://www.cancerresearchuk.org/health-professional/ early-diagnosis-activities/be-clear-on-cancer/lung-cancer-campaign (accessed: 11 Apr 2015).

22. Power E, Wardle J. Change in public awareness of symptoms and perceived barriers to seeing a doctor following Be Clear on Cancer campaigns in England. Br J Cancer 2015;112(Suppl 1):S22-6.

23. Cancer Research UK. Be Clear on Cancer 2010. http://www. cancerresearchuk.org/health-professional/early-diagnosis-activities/ be-clear-on-cancer (accessed: Jul 2015).

24. Thygesen LC, Daasnes C, Thaulow I, et al. Introduction to Danish (nationwide) registers on health and social issues: structure, access, legislation, and archiving. Scand J Public Health 2011;39:12-16.

25. Rasmussen S, Sondergaard J, Larsen PV, et al. The Danish Symptom Cohort: Questionnaire and Feasibility in the Nationwide Study on Symptom Experience and Healthcare-Seeking among 100 000 individuals. Int J Family Med 2014;2014:187280.

26. Whitaker KL, Scott SE, Winstanley K, et al. Attributions of cancer 'alarm' symptoms in a community sample. PLOS ONE 2014;9: e114028.

27. Nakash RA, Hutton JL, Lamb SE, et al. Response and non-response to postal questionnaire follow-up in a clinical trial-a qualitative study of the patient's perspective. J Eval Clin Pract 2008;14:226-35.

28. Galea S, Tracy M. Participation rates in epidemiologic studies. Ann Epidemiol 2007;17:643-53

29. Hohwu L, Lyshol H, Gissler M, et al. Web-based versus traditional paper questionnaires: a mixed-mode survey with a Nordic perspective. J Med Internet Res 2013;15:e173.

30. Steen N, Hutchinson A, McColl E, et al. Development of a symptom based outcome measure for asthma. BMJ 1994;309:1065-8.

31. Stull DE, Leidy NK, Parasuraman B, et al. Optimal recall periods for patient-reported outcomes: challenges and potential solutions. Curr Med Res Opin 2009;25:929-42.

32. McColl E. Best practice in symptom assessment: a review. Gut 2004:53(Suppl 4):iv49-54.

33. Jenkins P, Earle-Richardson G, Slingerland DT, et al. Time dependent memory decay. Am J Ind Med 2002;41:98-101.

34. Connor Gorber S, Schofield-Hurwitz S, Hardt J, et al. The accuracy of self-reported smoking: a systematic review of the relationship between self-reported and cotinine-assessed smoking status. Nicotine Tob Res 2009;11:12-24.

35. Connor Gorber S, Tremblay M, Moher D, et al. A comparison of direct vs. self-report measures for assessing height, weight and body mass index: a systematic review. Obes Rev 2007;8:307-26.

36. Heller WD, Scherer G, Sennewald E, et al. Misclassification of smoking in a follow-up population study in southern Germany. J Clin Epidemiol 1998;51:211-18

37. Crutzen R, Goritz AS. Social desirability and self-reported health risk behaviors in web-based research: three longitudinal studies. BMC Public Health 2010;10:720.

38. Del Boca FK, Darkes J. The validity of self-reports of alcohol consumption: state of the science and challenges for research. Addiction 2003;98(Suppl 2):1-12.

39. Rothman KJ. Epidemiology: an introduction. New York: Oxford University Press, 2012:133-6. 
40. Zang EA, Wynder EL. Reevaluation of the confounding effect of cigarette smoking on the relationship between alcohol use and lung cancer risk, with larynx cancer used as a positive control. Prev Med 2001;32:359-70.

41. Gupta S, Hassan S, Bhatt VR, et al. Lung cancer trends: smoking, obesity, and sex assessed in the Staten Island University's lung cancer patients. Int J Gen Med 2014;7:333-7.

42. Petrie KJ, Faasse $\mathrm{K}$, Crichton $\mathrm{F}$, et al. How common are symptoms? Evidence from a New Zealand national telephone survey. BMJ open 2014; 4:e05374.
43. Corner J, Hopkinson J, Roffe L. Experience of health changes and reasons for delay in seeking care: a UK study of the months prior to the diagnosis of lung cancer. Soc Sci Med 2006;62:1381-91.

44. Smith SM, Campbell NC, MacLeod U, et al. Factors contributing to the time taken to consult with symptoms of lung cancer: a cross-sectional study. Thorax 2009;64:523-31.

45. Tod AM, Craven J, Allmark P. Diagnostic delay in lung cancer: a qualitative study. J Adv Nurs 2008;61:336-43.

46. Dave D, Saffer H. Alcohol demand and risk preference. J Econ Psychol 2008;29:810-31. 